\title{
Society for Medicinal Plant and Natural Product Research: Bionorica Phytoneering Award and Egon Stahl-Award
}

\section{Announcement Bionorica Phytoneering Award 2013 \\ $\nabla$}

BIONORICA SE is globally one of the leading companies in the area of phytotherapy, producing plant-based medicines with proven efficacy, safety and quality. BIONORICA's headquarters are located in Neumarkt i. d. Opf. (Germany/Bavaria). The company is family-owned since 80 years.

A significant focus of BIONORICA's work is concentrated on R \& D activities with annual capital investments of about $15 \%$ of the company's turnover. Although the center of all R \& D activities is in Neumarkt, BIONORICA has established further research institutes in Innsbruck (Austria) and Hong Kong. In addition BIONORICA has built a scientific network with multiple renowned institutions, organizations and scientists worldwide.

The Bionorica Phytoneering Award (BPA) acknowledges outstanding research and development with regard to medicinal plants. The award is endowed with $10000 €$.

The purpose of the award is to motivate scientists (normally younger than 45 years of age) all over the world to perform research with regard to herbal drugs focusing on the following:

Generally any new discovery and innovative application related to

- phytoanalytics/pharmacokinetics/pharmacodynamics/phytomedicine

- analytical approaches including active principles/metabolomic approaches

- research leading to the identification of new pharmacological mechanisms

- new techniques especially applied for herbal drugs

Bibliography

DOI http://dx.doi.org/

10.1055/s-0032-1333281

Drug Res 2013;

63: 2-3 @ Georg Thieme Verlag KG Stuttgart · New York ISSN 2194-9379

Correspondence

Prof. Dr. Wolfgang Blaschek

Pharmaceutical Biology

Institute of Pharmacy

University of Kiel

Gutenbergstraße 76

24118 Kiel

Germany

wbla@pharmazie.uni-kiel.de
Scientists or research groups of universities and other noncommercial scientific institutions are entitled to apply. 3 scientific publications on a specific topic which have been published during the last 3-5 years can be considered. They must be submitted in electronic form (as CD in 5 copies) until April 15, 2013 along with a CV and a list of publications to the President of the GA (Society for Medicinal Plant and Natural Product Research), Prof. Dr. Wolfgang Blaschek, Kiel.

The Bionorica Phytoneering Award will be bestowed during the $61^{\text {st }}$ International GA congress in Münster (Germany), September 1-5,
2013 (www.ga2013.org). The award-winner will present the scientific results during the congress in a lecture of $30 \mathrm{~min}$.

Prof. Dr. Wolfgang Blaschek, GA President

Documents to be sent to:

Prof. Dr. Wolfgang Blaschek

Pharmaceutical Biology,

Institute of Pharmacy

University of Kiel

Gutenbergstraße 76

24118 Kiel, Germany

E-Mail: wbla@pharmazie.uni-kiel.de 


\section{Egon Stahl-Award in Silver 2013}

\section{$\nabla$}

On the occasion of his $60^{\text {th }}$ birthday, Professor Dr. Dr. h.c. mult. Egon Stahl donated a medal, a document and a monetary prize in order to recognize and promote young scientists working in the field of Pharmacognosy (Pharmaceutical Biology) and Analytical Phytochemistry.

As a rule, the silver medal and an award of $€ 3000$ should be awarded to scientists up to the age of about 40, who have published outstanding scientific work during the years following their graduation.

In 2013 the ESA Silver will be given during the $61^{\text {st }}$ International Congress and Annual Meeting of GA in Münster, Germany, 1-5 Sept. 2013 (www.ga2013.org).

Members of the Society for Medicinal Plant and Natural Product Research (GA) are invited to submit nominations for candidates together with supporting data to the president of GA, Prof. Dr. Wolfgang Blaschek, Kiel.

A nomination for the prize has to include a curriculum vitae incorporating the candidate's scientific career, an index on her/ his publications, and reprints of several of his/her more recent publications. All publications can be taken into consideration.

All documents have to be submitted in electronic form (as CD in 5 copies). Deadline for submission is $\mathbf{1 5}$ March 2013.

\section{Documents to be sent to:}

Prof. Dr. Wolfgang Blaschek

Pharmaceutical Biology

Institute of Pharmacy

University of Kiel

Gutenbergstraße 76

24118 Kiel, Germany

E-Mail: wbla@pharmazie.uni-kiel.de 